\title{
LA DISTRIBUCIÓN SOCIAL DE LA TIERRA EN EL BAJO MIÑO (1600-1850). ¿ES POSIBLE EL EXCEDENTE CAMPESINO EN COMUNIDADES MINIFUNDISTAS? ${ }^{1}$
}

\author{
SOCIAL DISTRIBUTION ON THE \\ BAJO MIÑO (1600-1850). IS PEASENT SURPLUS \\ POSIBLE IN SMALL FARMING COMUNITIES?
}

\author{
JOSÉ MANUEL PÉREZ GARCÍA \\ Universidad de Vigo
}

\begin{abstract}
Resumen
Con un uso cruzado de fuentes: inventarios post-mortem recogidos de 61 notarías de Pontevedra y Tuy y tres parroquias vaciadas de los libros reales del Catastro de Ensenada (326 explotaciones) pretendemos adentrarnos en la sociedad del Bajo Miño a lo largo de casi tres siglos. Antes de proceder al análisis de esta sociedad propiamente dicha fue necesario pulir las fuentes manejadas, quizás la parte más laboriosa del presente trabajo y aproximarnos a la evolución de variables claves como las rentas, los rendimientos o la evolución de los cultivos para delimitar la relación entre el producto bruto y el producto neto medio por Ha. cultivada. La tendencia de la productividad neta por Ha. es de claro ascenso y al producirse esto en un contexto de estabilidad de la renta foral unido a la progre-
\end{abstract}

\begin{abstract}
Using differente sources such as postmortem inventories, collected from 61 notary's offices from Pontevedra and Tuy, and taking the Catastro de la Ensenada's royal books from three parishes, we mean to penetrate in the Bajo Miño's society for almost three centuries. Before getting into the analysis of this society it was necessary to polish the sources which were being used, which might have been the most ardous part of the present work, and get close to the evolution of key variabilities such as income, yield or the cultivation evolution to delimitate the relation between gross product and average net product per Ha cultivated. The tendence of net productivity per Ha is climbing and, being thus produced in a foral income stability
\end{abstract}

${ }^{1}$ Recibido/Received 27.03.2010. Aceptado/Accepted 30.04.2010 
siva reducción de la semilla necesaria por la imposición creciente del maíz resulta que el mayor beneficiado del avance fuera el propio campesino explotador directo.

El estudio evolutivo de la sociedad nos sitúa ante un modelo minifundista y deficitario en el siglo XVII en donde el modelo agrario, a pesar del éxito impositivo del maíz, fue incapaz de hacer frente al impetuoso avance de la población generando una gran marea de campesinos insuficientes necesitados de las necesarias salidas migratorias en la búsqueda de recursos complementarios. En el siglo XVIII, ahora en un cuadro de situación maltusiana y práctico estancamiento de la población, nuestra sociedad alcanza una especie de madurez y equilibrio sin que variasen de manera sustancial sus estructuras salvo pequeños avances y ello gracias a la emigración que alcanza sus topes y a un ganadería complementaria con un reparto más igualitario que el del terrazgo. En el siglo XIX, en el marco de un afinamiento importante de un modelo productivo ya muy perfeccionado, nuestra comarca ya es excedentaria y de hecho exporta notables cantidades de cereales y vino. Esta marcha evolutiva de la insuficiencia estructural comarcal a las posibilidades reales de exportación de excedentes se acompañó de una creciente polarización social de tal manera que el minifundio dominante retrocedió y esto no impidió la consolidación y reforzamiento de una minoría campesina privilegiada capaz de acumular al final de nuestro recorrido unos excedentes netos que son superiores a las moderadas rentas que soportaba este modelo social.

\section{Palabras clave}

Minifundio, producto neto, excedentes y polarización social. along with the progressive reduction of the seed needed by the growing corn imposition, ends up having the peasant exploiter as the biggest beneficiary.

The evolutive study of this society puts us in front a small farming model which shows a deficit in the seventeenth century when the agricultural model, in spite of the impositice success over corn, was incapable of standing up to the growing population, generating a big flood of unsufficient peasents needed in the migratory exits on the quest for complementary resources. On the eighteenth century, in a setting of malthusian situation and the population on a standstill, our society reaches somewhat a maturity and balance, keeping its structures without a substancial alteration other than small advantages thanks to emigration, which reaches its peak, and a complementary cattle raising, with a more equal share than that of the land. On the nineteenth century having improved the productive model, already quite perfected, our shire already produces a surplus and it exports important quantities of cereal and wine. This evolutive march from the shire's structural insuffiency to the real surplus exportation possibilities happened along with an increasing social polarization in a way that the dominant small farm went back a step but didn't stop the consolidation and the enforcement of a privileged peasent minority able to accumulate, at the end of our overrun, a net surplus superior to the moderate income which this social model used to have.

\section{Keywords}

Small farm, net product, surplus and social polarization. 


\section{PRESENTACIÓN}

Pretendemos abordar nuestro estudio social en una comarca meridional de Galicia, el Bajo Miño, que se extiende sobre una territorio de unos $300 \mathrm{Km} 2$ teniendo como centro a Tuy, capital de la provincia más densamente poblada de las 7 que componían el Reino de Galicia durante la Edad Moderna. Esta comarca, aunque ya con cierta ventaja, estaba moderadamente poblada cuando comenzamos nuestro recorrido de 250 años con cerca de 40 habts/Km2 pero al final del mismo las cosas habían cambiado al multiplicarse sus efectivos demográficos por más de 3 conformando un auténtico hormiguero humano donde ya se alcanzaban los 129 habts/Km2. Trataremos de analizar como afectó esta crucial transformación a la sociedad minifundista que caracteriza a Galicia en general y a esta Vega Baja del Miño en particular tratando de adecuarla a las tres grandes fases demográficas que caracterizaron a este modelo ${ }^{2}$. Para alcanzar nuestros objetivos contamos con la información extraída de dos fuentes fundamentales:

a) Los protocolos notariales que nos han proporcionado un total de 873 inventarios post-mortem que cubren el período de 1625 a 1853 y 45 partijas de cronología más tardía ya que casi todas ellas son posteriores a 1750. De este conjunto de más de 900 escrituras, por las razones que luego analizaremos, sólo son "utilizables" para nuestros fines $571^{3}$, muestra que consideramos representativa. Para conseguirlas hubo que hacer un barrido exhaustivo sobre un total de 61 escribanías ${ }^{4}$.

b) Los libros reales del Catastro del Marqués de la Ensenada de tres parroquias que fueron tomadas tras una larga y laboriosa investigación previa. Descartada la parte centro-occidental de la comarca por la inconsistencia de las declaraciones catastrales ${ }^{5}$. Las parroquias que aquí hemos seleccionado de

2 Para una precisa información sobre estas fases remitimos a nuestro trabajo: "De la escasez a la precoz saturación: el desarrollo demográfico de la comarca del Bajo Miño (1550-1850)". De inmediata aparición en Cuadernos Feijonianos de Historia Moderna, III, Santiago, 2006.

3 De un total de 920 escrituras debemos descartar de entrada 349 porque en numerosos casos nuestros inventarios sòlo describen bienes mobiliarios y no hacen referencia a los bienes raíces imprescindibles en la presente investigación. También hemos de descartar recuentos y partijas de difuntos urbanos de Tuy y La Guardia así como de los marineros del núcleo guardés porque sólo nos interesan las familias propiamente rurales

4 Todas ellas están ubicadas en el Archivo Histórico Provincial de Pontevedra en su Fondo de Protocolos (A.H.P.P., F.P.). También se encuentran algunos escribanos depositados en el Archivo Diocesano de Tuy de los que se ha hecho un uso secundario.

5 Una minuciosa exposición de los graves problemas que plantea el Catastro de Ensenada en el Bajo Miño en PERÉZ GARCÍA, J. M., "Un chequeo al Catastro del Marqués de la Ensenada en la comarca del Bajo Miño”. Cuadernos Feijonianos de Historia Moderna, Santiago, 1999. 
los actuales municipios de Tuy (Areas y Paramos) y de Salceda de Caselas (Guillarey) suman 326 explotaciones y creemos que representan de manera adecuada a nuestra comarca ${ }^{6}$.

Sin embargo las informaciones que nos ofrecen ambas fuentes presentan serios problemas que deben ser previamente resueltos. Los inventarios son especialmente abundantes en nuestra comarca pero presentan notables insuficiencias: no existe problema alguno a la hora de retener los datos que nos ofrecen los que se refieren a solteros/as, viudos/as, clérigos y los escasos inventarios de pareja conyugal que en todos ellos reflejarían tamaños reales de explotaciones rurales pero no sucede lo mismo cuando la persona inventariada es una persona casada que son los más abundantes. En este caso las escrituras elaboradas de los bienes del difunto/a por nuestros notarios sólo recogen las fincas del implicado, así como de los bienes gananciales adquiridos durante el matrimonio, pero guarda silencio con las propiedades del cónyuge superviviente. Emplear así estas numerosas escrituras que aglutinan casi los 3/4 de la muestra lastraría gravemente nuestros resultados; no hacerlo dañaría muy gravemente la representatividad de nuestra muestra. ¿Es posible emplearlas corrigiendo la desviación que se produce? La tabla que hemos elaborado creemos que resuelve esta grave laguna. Veamos:

Tabla $n^{\circ}$ 1.- Distribución sectorial de los inventarios disponibles (en Has.) entre 1625 y 1853

\begin{tabular}{|c|c|c|c|c|c|c|}
\hline Situación del inventariado & $\begin{array}{c}\mathrm{N}^{\mathbf{0}} \\
\text { casos }\end{array}$ & $\begin{array}{c}\text { Tierra } \\
\text { cultivada }\end{array}$ & $\begin{array}{c}\text { Media } \\
\text { explotación }\end{array}$ & $\begin{array}{c}\text { Tierra } \\
\text { inculta }\end{array}$ & $\begin{array}{c}\text { Media } \\
\text { explotación }\end{array}$ & $\begin{array}{c}\text { Media } \\
\text { global }\end{array}$ \\
\hline $\begin{array}{c}\text { Solteros/viudos/clérigos y } \\
\text { matrimonios }\end{array}$ & 145 & 103,87 & 0,72 & 25,24 & 0,17 & 0,89 \\
\hline Casados & 315 & 113,43 & 0,36 & 21,66 & 0,07 & 0,43 \\
\hline Casadas & 92 & 36,94 & 0,40 & 5,89 & 0,06 & 0,46 \\
\hline Total casados y casadas & 407 & 150,37 & 0,37 & 27,55 & 0,07 & 0,44 \\
\hline
\end{tabular}

La Tabla nos arroja dos conclusiones de gran interés: a) Que independientemente de que el inventariado sea el esposo o esposa difunto la explotación media que deja a su muerte es muy similar tanto en lo que se refiere a las parcelas cultivadas como a las incultas por eso globalmente son muy parecidas $(0,43$ y 0,46 Has); b) Que la explotación media del conjunto de los esposados viene a ser casi exactamente la mitad de las explotaciones completas del primer bloque que pode-

${ }^{6}$ Nuestras tres parroquias arrojan una explotación media de 1,12 Has casi idénticas a la media de las 19 feligresías que componen el conjunto centro oriental de la comarca que responden con más garantías en nuestra fuente fiscal y que ofrecen una media de 1,10 Has en las Respuestas Generales. según nuestros cálculos. 
mos considerar como explotaciones completas ( 0,89 frente a 0,44 Has.). Así que si multiplicamos por 2 los bienes de los difuntos/as casados contenidos en los inventarios tendríamos casi la explotación de la familia campesina. Sólo nos restaría sumar los bienes gananciales adquiridos durante matrimonio que afectan a todo el conjunto de la muestra y que habíamos retirado para hacer viable la comparación.

El correcto vaciado de los libros reales del Catastro de Ensenada no está tampoco exento de problemas. En una primera aproximación nos encontramos con la no coincidencia de las extensiones contempladas en las Respuestas Generales parroquiales descritas en la pregunta 9 con las contenidas en los asientos particulares de los libros reales ${ }^{7}$. Además de las contradicciones internas como elevar sustancialmente las tierras cultivadas en las primeras y hacer lo propio con las superficies incultas en las segundas quizás buscando una intencionada ocultación de las tierras más productivas no debe despreciarse esa diferencia global del $32 \%$ entre ambas respuestas que nos obliga a buscar la adecuada solución. Veamos:

Tabla $n^{\circ}$ 2.- Contraste entre las respuestas particulares y generales del Catastro de Ensenada en el conjunto de las tres parroquias seleccionadas (Has).

\begin{tabular}{|c|c|c|c|c|}
\hline Dedicación & Particulares (A) & Generales (B) & $\begin{array}{c}\text { Media } \\
\text { explotación en (A) }\end{array}$ & $\begin{array}{c}\text { Media } \\
\text { explotación en (B) }\end{array}$ \\
\hline Labradío & 173,54 & 294,06 & 0,53 & 0,90 \\
\hline Viñedo & 39,33 & 102,26 & 0,12 & 0,31 \\
\hline Inculto & 153,75 & 89,37 & 0,47 & 0,27 \\
\hline Conjunto & 366,62 & 485,68 & 1,12 & 1,48 \\
\hline
\end{tabular}

Cometeríamos un craso error si nos limitáramos a tomar las explotaciones familiares a partir de los datos contenidos exclusivamente en los asientos reales de las tres parroquias seleccionadas. Dada las características propias del paisaje minifundista de esta Galicia meridional es muy frecuente que las familias campesinas compartan parcelas en varias parroquias fruto de las relaciones matrimoniales y del sistema hereditario dominante. Esto nos obligó a consultar las parroquias colindantes a las tres estudiadas y vaciar de un conjunto complementario de otras 13 parroquias las parcelas que nuestras familias disfrutaban en ellas. El resultado de esta laboriosa búsqueda es como sigue (en ferrados de $437 \mathrm{~m} 2$ ):

${ }^{7}$ En buena medida esta disociación se produce al introducirse en cada parroquia un volumen importante y variable de tierras de forasteros, los más pertenecientes a vecinos de parroquias colindantes. También puede influir el hecho de que los datos de las Respuestas Generales se ofrecen por redondeo. 


\begin{tabular}{|c|c|c|c|c|c|c|c|c|c|}
\hline \multicolumn{4}{|c|}{ Areas } & \multicolumn{3}{c|}{ Entienza } & \multicolumn{3}{c|}{ Paramos } \\
\hline Dedicación & Propia & Colindante & $\%$ & Propia & Colindante & $\%$ & Propia & Colindante & $\%$ \\
\hline Labradío & 862,58 & 28,25 & 3,3 & $1.539,85$ & 209,45 & 13,6 & $1.568,63$ & 750,93 & 47,9 \\
\hline Viñedo & 133,87 & 1,42 & 1,1 & 557,85 & 53,05 & 9,5 & 228,33 & 59,73 & 26,2 \\
\hline Inculto & 774,44 & 76,78 & 9,9 & $1.603,68$ & 166,38 & 10,4 & $1.140,5$ & 717,74 & 63,0 \\
\hline Totales & $1.770,89$ & 106,45 & 6,0 & $3.701,38$ & 428,88 & 11,6 & $2.037,11$ & $1.528,40$ & 52,0 \\
\hline
\end{tabular}

Sólo en una de las parroquias - Areas - las desviaciones que cometeríamos serían casi despreciables pero ya serían significativas en Entienza y capitales en Paramos lo que compensa con creces el tiempo invertido y da una mayor exactitud a nuestras cifras. De hecho si aglutinamos las tres parroquias tendríamos este interesantísimo resultado:

\begin{tabular}{|c|c|c|c|}
\hline Dedicación & Propias parroquias (A) & Parr. Colindantes (B) & $\%$ B sobre A \\
\hline Labradío & $3.971,06$ & 988,63 & 24,9 \\
\hline Viñedo & 900,5 & 114,20 & 12,7 \\
\hline Inculto & $3.518,27$ & 960,90 & 27,3 \\
\hline Totales & $8.389,83$ & $2.063,73$ & 24,6 \\
\hline
\end{tabular}

La síntesis que nos ofrece la tabla nos indica que casi el 25\% de las tierras contenidas en nuestras explotaciones recompuestas se nos escaparían cometiéndose un sesgo importante. Además esos más de 2.000 ferrados (90,2 Has.) localizados en las parroquias limítrofes constituyen la mayor parte de de las 119 Has. supuestamente desaparecidas en las Respuestas Particulares al ser contrastadas con las Generales. Las 29 Has que todavía nos faltan, que representan un porcentaje muy modesto del $6,3 \%$, habría que interpretarlas como tierras ubicadas en otras parroquias inmediatas a las limítrofes o a disfrutes desiguales entre autóctonos y forasteros de las parroquias elegidas pero no serían imputables a las contradicciones de la fuente.

Eso no quiere decir que el Catastro de Ensenada no presente problemas además de los ya señalados. Hemos apreciado una ocultación importante a la hora de declarar los rendimientos ${ }^{8}$ y también tenemos sospechas razonables de una ocultación

${ }^{8}$ Los rendimientos catastrales en el Bajo Miño fueron de 21Hl/Ha pero los reales se situaban entre los 27 y los $28 \mathrm{Hl}$. lo que supone una ocultación del 25\%. Vid. PÉREZ GARCÍA, J. M., "Un chequeo....", op. cit., p. 173 y apéndice p. 192. Esta ocultación no era exclusiva de Bajo Miño y es así que en la comarca orensana de Celanova el porcentaje se elevaba al 38\% al declarar 17,2 cuando los reales se situaban entre los 26,7 y 27,7 Hl./Ha. Dato procedente de la Tesis Doctoral prácticamente terminada de nuestra discípula RODRÍGUEZ FERNÁNDEZ, D., "Hogar, parentela y vecindad. Familia y reproducción social en tierras de Celanova a lo largo de la edad moderna, S. XVIII-XIX". Para el 
en las extensiones a nivel de la comarca aunque probablemente más modesta en nuestra selección ${ }^{9}$. Un estudio del tamaño de las parcelas contrastando las cifras contenidas en los inventarios y partijas con las del Catastro parece apuntar a esta desviación. En efecto sobre 61 inventarios controlados entre 1747 y 1781 en una fase de casi estabilidad demográfica y sobre más de 400 parcelas de labradío/viñedo tendríamos una parcela media de $520 \mathrm{~m} 2$ que frente a $10 \mathrm{~s} 406 \mathrm{~m} 2$ del Catastro sobre más de 5.000 parcelas arrojaría una desviación del 28\%. Si quisiéramos aumentar la muestra con 14 partijas de 1751 a 1798 alcanzaríamos sobre unas 750 parcelas una parcela media de $494 \mathrm{~m} 2$ con que la diferencia sería un superávit del $21 \%$ con relación a la fuente fiscal. Si estas diferencias fueran correctas es muy probable que la ocultación pudiera aproximarse al $25 \%^{10}$.

Todavía necesitamos fijar ciertos parámetros a fin de analizar las estructuras sociales y abordar la cuestión clave de los excedentes. Lo primero que necesitamos, y no fácil de resolver, es la cuestión de los rendimientos cerealeros: es verdad que no tenemos problemas para dos de las tres etapas aquí estudiadas por haber abordado esta cuestión en un trabajo ya publicado ${ }^{11}$. El problema estriba en establecer el nivel de rendimientos para el siglo XVII sin fuentes directas para ello. Hemos ensayado resolverlo con una treintena de adecuados inventarios situados entre 1652 y 1679 y escriturados entre mediados del mes de septiembre y mediados del mes de octubre que podrían ser considerados como indicativos de unas despensas cam-

conjunto de la Galicia litoral Occidental el Catastro nos ofrece unos rendimientos de 15,61 $\mathrm{Hl}$. Ha pero posiblemente habría que elevarlos a 23,67 lo que significaría una ocultación del 34\%. Vid. PÉREZ GARCÍA, J. M., "A agricultura de mediados do século XVIII a través dos seus rendementos. Unha desposta alternativa", Revista galega de estudios agrarios, $\mathrm{n}^{\circ}$ 6, 1982, pp. 36-37.

9 Sobre una media global de las tres parroquias alcanzamos una explotación media de 1,12 Has de tierra cultivada e inculta pero esta oscila entre las 1,27 Has. de Entienza, las 1,13 de Areas y las 0,95 de Paramos. La superioridad de 1/3 en la primera parece indicarnos una probable ocultación en Paramos.

10 No sería muy distante del 30\% que en su día estimamos para el Salnés de manera mucho más rigurosa. Vid. PÉREZ GARCÍA, J. M., Un modelo de sociedad rural de Antiguo Régimen en la Galicia costera, Univ. Santiago, 1979, pp. 35-43. Apréciese de pasada el tamaño reducidísimo de nuestras parcelas. Para el conjunto del litoral de las Rías Bajas hemos encontrado para el siglo XVIII una parcela media en inventarios de $780 \mathrm{~m} 2$ y en partijas de 1.163 muy superiores a las minotas. Vid. PÉREZ GARCÍA, J. M., "Transformación y consolidación de un paisaje rural: minifundio y parcelación en las Rías Bajas Gallegas". En Paisajes et sociétés. Mélanges Géographiques en l'honneur du Professeur Alain Bouhier, Univ. Poitiers, 1990, p.62.

${ }^{11}$ Con una amplia muestra de patrimonios eclesiásticos hemos establecido una larga serie para medir la evolución de los rendimientos en los siglos XVIII y XIX. Aquí emplearemos para las dos últimas fases valores medios extraídos de nuestro trabajo: "En los límites del virtuosismo agrario tradicional: la fertilidad de la comarca del Bajo Miño (1730-1860)". Ler Historia, no 36, 1999, tabla n ${ }^{\circ}$, pp. 226-27. 
pesinas dominadas ya por entonces por el maíz que representaría ya el 89,8\% del granero en esta muestra. Si relacionamos estos inventarios-cosecha con las explotaciones reconstruidas de estos mismos inventarios tal y como indicamos con anterioridad, podríamos acercarnos a los rendimientos meramente aproximativos del momento. El resultado que aplicaríamos al presente trabajo quedaría así:

$$
\begin{aligned}
& \text { 1652-1679.....18,69 Has....Produjeron } \quad 450 \mathrm{Hl} \ldots . \text { Rendimientos } 24,1^{12} \\
& 1736-1789 \ldots 146,02 \text { Has.... } \quad \text { “ } 3.930 \mathrm{Hl} \ldots . . \text { Rendimientos } 26,9 \\
& \text { 1790-1859...144,97 Has..... “ “ } 4.417 \text { Hl.... Rendimientos 30,5. }
\end{aligned}
$$

Más delicado es establecer para cada etapa los niveles de punción que sufren las explotaciones campesinas y poder así acercarnos aunque sea de manera aproximativa al producto neto disponible para cada período. Si admitimos los rendimientos como base de fijación del producto bruto podemos estimar las detracciones que este sufre y que serían las siguientes: el diezmo lo estimamos en el 7\% según la determinación precisa que podemos establecer a partir del Catastro de Ensenada para el conjunto de los dos municipios aquí seleccionados y creemos que esta punción no debió sufrir alteraciones serias salvo en el último período por efecto de una contestación creciente y por su eliminación en 1835 por lo que 15 de los 60 años de la fase no lo pagaron y por lo ello debemos reducirlo al menos en un $25 \%$ y dejarlo en un 5,25\%. Sabemos también que la renta foral permanece prácticamente estabilizada desde las primeras décadas del XVII ${ }^{13}$ y que fueron muy escasas las reden-

12 De manera excepcional los inventarios pueden ofrecernos rendimientos sobre parcelas concretas. En efecto, en el inventario de Agustín González se nos dice que 4 parcelas que suman 4,5 ferrados de superficie han producido 24 ferrados de maíz, 2 ferrados de trigo y 3 ferrados de centeno con lo que significa un rendimiento de 6,4 por 1 explicable por la cosecha mayoritaria de maíz (A.H.P.P., F.P., libro 2, 7-XI-1663). En el de Simón González escriturado el 15-X-1669, el escribano anotó 2 fincas de 1 ferrado de extensión cada una de las que se cogió 6 ferrados de centeno en cada una de ellas lo que representa un rendimiento de 6 x 1 (A.H.P.P., F.P., Caja 3.825). También en el inventario de Juan Alonso Flores registrado en 20-VII-1687, constan dos fincas que suman 3,5 ferrados de superficie y que produjeron 18 ferrados de centeno y trigo, sea una rato de 5,1 (A.H.P.P., F.P. libro 6). Estos rendimientos ocasionales en superficie casan bien con $\operatorname{los} 24,1 \mathrm{Hl}$.Ha que hemos establecido equivalentes a unos rendimientos en superficie de 5,16.

13 Así lo estima P. Saavedra a partir de los numerosos estudios disponibles lo que le lleva a afirmar que la renta foral se denota inadecuada para absorber los incrementos de la producción agraria. Vid SAAVEDRA, P., "Consideraciones sobre la renta de la tierra y la comercialización de excedentes agrarios en la España del Antiguo Régimen", Noticiario de Historia Agraria, nº 5, 1993, pp. 17-18. Para el mantenimiento de las ratio forales y las escasas diferencias intercomarcales al menos para las dos últimas fases vid. PÉREZ GARCÍA, J. M., "El régimen subforal en la Galicia Occidental entre 1740 y 1850. Muestreos comarcales", Obradoiro de Historia Moderna, n 4, 1995, tablas 3 y 6, pp. 77-79. 
ciones forales campesinas en nuestra tercera etapa por lo que podemos fijar como base de cálculo los resultados que hemos establecido para mediados del siglo XVIII a partir de los datos del Catastro de Ensenada que nos llevan a cuantificar su punción en un $11 \%$ de las cosechas ${ }^{14}$ y que aplicaremos a la fase 1681 a 1790. Para los períodos anterior y posterior podemos recurrir a una muestra razonable de foros encuadrados en la comarca del Bajo Miño y de este estudio se comprueba, una vez más, la estabilidad de la renta foral en la larga duración ${ }^{15}$; la elevación de las rentas forales en la aplicación de sus ratios quedó absorbida en la paralela elevación de los rendimientos por lo que su peso real con relación al producto bruto siguió siendo prácticamente estable en torno al $11 \%$ que estimamos para la fase central de este estudio. Veamos:

\begin{tabular}{|l|l|l|l|l|l|}
\hline Fases & $\mathrm{N}^{\circ}$ foros & $\begin{array}{l}\text { Extensión } \\
\text { (Has.) }\end{array}$ & Renta en (Hl.) & $\begin{array}{l}\text { Renta en } \\
\text { Hl./Ha. }\end{array}$ & $\begin{array}{l}\% \text { sobre } \\
\text { producción }\end{array}$ \\
\hline $1600-1688$ & 123 & 40,54 & 107,58 & 2,65 & 11,0 \\
\hline $1791-1853$ & 242 & 100,86 & 346,87 & 3,44 & 11,3 \\
\hline
\end{tabular}

También podemos establecer de manera muy segura el peso de la semilla a partir de la preciosa información contemplada en las Respuestas Generales del Catastro de Ensenada para mediados del XVIII pero como la composición de la despensa campesina sufrió importantes modificaciones a lo largo del período aquí analizado debemos ajustar, con la ayuda de los inventarios, el empleo de la semilla a los cereales realmente sembrados en cada una de las fases a partir de la composición de los graneros. Todavía nuestro campesino deberá hacer frente a una serie de cargas ya menos importantes que suponen las obligaciones piadosas (misas, responsos, anales de cofradías, etc.), los empeños que pesan sobre las explotaciones (censos y obligaciones), las rentas jurisdiccionales y las cargas fiscales que también hemos establecido para mediados del XVIII en el 3,5\% de las cosechas, porcentaje que hemos mantenido para todo el período ante la imposibilidad de cualquier ajuste pero tal decisión no debe variar significativamente los datos finales. Los

14 Tanto los diezmos como las rentas forales proceden de tomar como buenos los datos conjuntos de las 18 parroquias de las zonas I y II correspondientes a las zonas Oriental y Centro-Oriental de nuestra comarca donde las declaraciones catastrales nos merecen más confianza. Vid. PÉREZ GARCÍA, J. M., “Un chequeo ......”, op. cit., Apéndice, tabla 6 A y B, pp. 187-88

15 Para cada período se han tenido en cuenta la naturaleza y las diferentes medidas de los cereales realmente pagados. Para las rentas en dinero hubo que reducirlas a ferrados de maíz - la renta foral más común de la zona - aplicando a cada período un precio medio procedente de los propios protocolos notariales que quedó fijado en 3 reales para la primera fase y en 9 para la última. 
resultados los ofrecemos en la siguiente tabla no sin recordar que a cada etapa se le ha aplicado los correspondientes rendimientos ya indicados. También que se refieren a estimaciones por Ha de cultivo cerealero:

Tabla $n^{\circ}$ 3.- Evolución del producto neto en la larga duración (1625-1853)

\begin{tabular}{|c|c|c|c|c|c|c|}
\multicolumn{4}{c}{} & \multicolumn{2}{c|}{$1^{\text {er }}$ corte $(1625-1680)$} & \multicolumn{2}{c|}{$2^{\circ}$ corte $(1691-1790)$} & \multicolumn{2}{c|}{$3^{\text {er }}$ corte $(1791-1853)$} \\
\hline Punciones & $\%$ & Hl. grano & $\%$ & Hl. grano & $\%$ & Hl. grano \\
\hline Diezmos & 7,0 & 1,69 & 7,0 & 1,88 & 5,25 & 1,60 \\
\hline Foros & 11,0 & 2,65 & 11,0 & 2,96 & 11,3 & 3,44 \\
\hline Otras cargas & 3,5 & 0,84 & 3,5 & 0,97 & 3,5 & 1,07 \\
\hline Semilla & 6,6 & 1,59 & 4,4 & 1,18 & 3,4 & $1,05^{16}$ \\
\hline Totales & 28,1 & 6,77 & 25,9 & 6,99 & 23,45 & 7,16 \\
\hline Producto neto & 71,9 & 17,33 & 74,1 & 19,91 & 76,5 & 23,34 \\
\hline
\end{tabular}

La tabla nos merece la confianza necesaria para que podamos concluir: a) Que este modelo agrario estaba sometido a un conjunto de detracciones de carácter muy moderado donde el producto neto mínimo garantizado sería próximo al $72 \%{ }^{17}$ y que contrastaba profundamente con las tierras lucenses de barbecho bienal donde tal producto cae a menos del $50 \%{ }^{18}$ lo que obedecía sobre todo al binomio rentas y diezmo que aquí se llevaba la tercera parte de las cosechas mientras que en nuestra comarca se limitaba a un baremo del 20 a 21,5\% y al ahorro de semilla que permite el cultivo dominante del maíz; b) Que los avances observados en los rendimientos del orden del $25 \%$ en la larga duración beneficiaron modestamente a los grupos rentistas pero el campesino sí se benefició como lo denota el avance decidido de su producto neto; c) En efecto, dicho producto neto por Ha. fue ascendente al pasar de unos $17 \mathrm{Hl} / \mathrm{Ha}$ en la primera fase a los casi 20 de la segunda y aún superar los 23 en la tercera determinando una subida de casi el $35 \%$ en la larga duración.

16 Esta acusada caída de las semillas empleadas por Ha. obedece al distinto peso de los cereales tradicionales en las despensas por el avance imparable del maíz que podría suponer el $75 \%$ del granero en la primera fase, $90 \%$ en la segunda y $95 \%$ en la tercera y al avance paralelo de los rendimientos.

17 Estas punciones que garantizaban un producto neto mínimo del $72 \%$ no eran exclusivas de la comarca del Bajo Miño. Estimaciones recientes han fijado en el Valle de Monterrey un producto neto del 73,4\% (GONZÁLEZ ABELLAS, I.C., "Valle y montaña: sociedad, grupos sociales y comercio en el Valle de Monterrey a mediados del siglo XVIII", Cuadernos Feijonianos de Historia Moderna, II, 2002, p. 215. También en la comarca de Celanova el producto neto era del 76/77\% establecido por RODRÍGUEZ FERNÁNDEZ, D. en la Tesis Doctoral antes mencionada.

18 En la meseta lucense se ha estimado en un 42 a 45\% según se parta de unos rendimientos de 4 ó 5x 1 siendo más probables los primeros. Vid. SOBRADO CORREA, H., Las tierras de Lugo en la Edad Moderna. Economía campesina, familia y herencia, 1550-1860, A Coruña, 2001, p. 209 
Es evidente que estos cambios afectan a la estructura social y a lo que entendemos por campesino insuficiente, medio o excedentario lo que nos obliga a ajustar las categorías para hacer comparables nuestros períodos. Teniendo en cuenta los cambios ocurridos en las diferentes variables ya analizadas las escalas quedarán establecidas así:

Tabla $n^{\circ}$ 4.- Diseño de las categorías sociales por etapas (ferrados de $437 \mathrm{~m} 2$ )

\begin{tabular}{|c|c|c|c|}
\multicolumn{2}{c}{$1^{\text {er }}$ corte $(1625-1680)$} & $2^{\text {o }}$ corte $(1691-1790)$ & $3^{\text {er }}$ corte $(1791-1823)$ \\
\hline Campesinos insuficientes & Menos de 17 & Menos de 15,5 & Menos de 13,5 \\
\hline Campesinos modestos & 17 a 34 & 15,5 a 31 & 13,5 a 27 \\
\hline Campesinos ricos & 34 a 68 & 31 a 62 & 27 a 54 \\
\hline Elites campesinas & Mas de 68 & Mas de 62 & Mas de 54 \\
\hline
\end{tabular}

Si traducimos a producción bruta estas escalas queremos indicar que aunque las explotaciones de nuestras categorías se van reduciendo esto no es sino el efecto de la subida de los rendimientos. Así los campesinos pobres tendrían tu techo igual en las tres fases que situamos en los $18 \mathrm{Hl}$. brutos de producción completamente deficitarios para la subsistencia familiar mientras que en el otro extremo nuestras élites tienen garantizados el mismo corte en los tres momentos que es un mínimo de 72 Hl. sin duda suficientes para garantizar notables excedentes.

\section{LA SOCIEDAD CAMPESINA EN EL SIGLO XVII (1625-1680)}

El marco en que se desarrolló esta sociedad agraria durante esta etapa coincidió casi con la introducción del maíz en la comarca, presente al menos desde 1638 -primera cita conocida- pero lo hizo con tal fuerza que en la última década que cierra la fase ya suponía el 87,3\% del granero. El resultado fue la euforia agraria, la explosión demográfica hasta alcanzar los 100 habs./Km2 y la gestación de unas fuertes corrientes migratorias ante la impotencia del aparato productivo para sostener este aluvión poblacional. Esto tiene un fiel reflejo el la sociedad que deducimos de nuestros inventarios. Veamos:

\section{Tabla $n^{\circ}$ 5.- La sociedad campesina en el siglo XVII (1625/1680)}

A) Distribución social de la tierra en cifras medias (Has.)

\begin{tabular}{|c|c|c|c|c|c|c|}
\hline Tipología social & $\mathrm{N}^{\circ}$ casos. & $\%$ & Labradío/mixto & Viña & Inculto & Total \\
\hline Elites campesinas & 5 & 2,8 & 3,11 & 0,55 & 0,70 & 4,25 \\
\hline Campesinos ricos & 21 & 11,7 & 1,56 & 0,31 & 0,09 & 1,96 \\
\hline Campesinos modestos & 43 & 23,9 & 0,86 & 0,10 & 0,08 & 1,04 \\
\hline Campesinos insuficientes & 111 & 61,6 & 0,37 & 0,05 & 0,02 & 0,44 \\
\hline Totales & 180 & 100 & 0,65 & 0,11 & 0,06 & 0,82 \\
\hline
\end{tabular}


B) Distribución del aprovechamiento del terrazgo (\%)

\begin{tabular}{|c|c|c|c|c|c|}
\hline Tipología social & Labradío/mixto & Viñedo & Inculto & Total Has. & $\%$ \\
\hline Elites campesinas & 71,4 & 12,6 & 16 & 21,77 & 17,8 \\
\hline Campesinos ricos & 79,5 & 15,8 & 4,6 & 41,22 & 28,1 \\
\hline Campesin. Modestos & 82,7 & 9,6 & 7,7 & 34,63 & 23,6 \\
\hline Campes. Insuficientes & 83,2 & 11,2 & 5,6 & 49,06 & 33,4 \\
\hline Totales & 79,2 & 12,9 & 7,9 & 146,68 & 100 \\
\hline
\end{tabular}

Con una explotación media global de 0,82 Has. de las que casi el $80 \%$ se destina a la producción cerealera - 0,65 Has. - esta sociedad está muy lejos de cubrir las necesidades alimenticias de la comarca. En efecto, con unos rendimientos de 24,1 $\mathrm{Hl} / \mathrm{Ha}$. y un producto neto ligeramente superior a los $17 \mathrm{Hl}$. una familia campesina media habría necesitado unas 0,95 Has. de superficie cultivada pera sobrevivir con lo justo. Tal situación provocaría un déficit global que podríamos estimar en un $31 \%$ y ni siquiera suponiendo que el total de las rentas se quedasen en la zona serían suficientes para garantizar la autosuficiencia generándose un déficit comarcal próximo al $10 \%$.

Sorprende sin duda encontrar un minifundio tan marcado en fechas tan tempranas sobre todo cuando se admite que en la Galicia Occidental las explotaciones medias se situarían a fines del XVI entre las 2 y las $5 \mathrm{Has}^{19}$ pero los datos no ofrecen la menos duda y podemos admitir que la comarca pagó un alto precio por la euforia demográfica del período. Si a los 111 campesinos insuficientes de la tabla sumamos los campesinos modestos que se quedan por debajo del corte de las 0,95 Has. de cultivo cerealero sumaríamos un total de 139 explotaciones, sobre 180, nada menos que el 77\% del total, que no tendrían garantizada la subsistencia. El resultado ya lo conocemos: la imperiosa búsqueda de recursos externos a través de la emigración ${ }^{20}$.

Sin embargo, una mirada atenta a la tabla no debe ocultar a ese $14,5 \%$ de las explotaciones de las categorías superiores que acaparan el $43 \%$ de la tierra y que serían capaces de generar excedentes sin duda modestos ${ }^{21}$ pero indiscutibles como ponen en claro nuestros inventarios. Un somero cálculo global nos indicaría que

19 Pueden consultarse las monografías de BOUHIER, A., La Galice. Essai géographie d'analyse et d'interpretation d'un vieux complexe agraire, La Roche-sur Yon, 1979, pp. 1.393/96 y GELABERT GONZÁLEZ, J., Santiago y la Tierra de Santiago de 1500 a 1640. La Coruña, 1982, 69.

${ }^{20}$ Nos hemos ocupado muy recientemente de esta cuestión en la comunicación presentada al VIII Congreso de la Asociación de Demografía Histórica titulada: "La intensa movilidad de la comarca del Bajo Miño (1600-1850)", Maón, 2007.

${ }^{21}$ Las 26 explotaciones que estarían en esta privilegiada situación disponer de una explotación media cerealera de cerca de 2 Has capaces de alcanzar una producción neta media de $31 \mathrm{Hl}$. 
estas 180 explotaciones podían alcanzar una producción global de unos $2.800 \mathrm{Hl}$. de los que las rentas se llevarían el $21,5 \%$ es decir unos $600 \mathrm{Hl}$.; sin embargo nuestros 26 campesinos excedentarios estarían en condiciones de producir casi 1.200 Hl. de los que habría que descontar las cargas que se llevarían nos $250 \mathrm{Hl}$., algo más de 400 para el sustento de sus familias y poco más de 75 Hl. para sembrar sus tierras lo que les permitiría disponer de algo más de $400 \mathrm{Hl}$. de excedentes cantidad bastante distante del capítulo de rentas. Los inventarios ponen en claro la potencialidad productiva y pocas veces rentista de estas élites rurales ${ }^{22}$ y la presencia de un interesante bloque de campesinos ricos con unas cotas nada invidiables ${ }^{23}$.

\section{LA SOCIEDAD CAMPESINA EN EL SIGLO XVIII (1681-1790)}

La nota que define al período es el estancamiento demográfico como lo indica el nivel de bautizados que apenas se mueve ${ }^{24}$ actuando como elemento capital de autocontrol las corrientes migratorias que alcanzaron la máxima intensidad las ultimas décadas de esta fase. Fue este control maltusiano el que permitió mantener nuestro modelo social con escasos cambios que nos hablan de una tímida mejora. Veamos:

Tabla $n^{\circ}$ 6.- La sociedad campesina en el siglo XVIII (1681-1790)

A) La distribución social de la tierra en cifras medias ( Has.).

\begin{tabular}{|c|c|c|c|c|c|c|}
\hline Tipología social & $\mathrm{N}^{\mathbf{o}}$ casos & $\%$ & Labradío/mixto & Viña & Inculto & Total \\
\hline Elites campesinas & 5 & 2,4 & 3,33 & 0,34 & 0,61 & 4,28 \\
\hline Campesinos ricos & 26 & 12,4 & 1,55 & 0,17 & 0,27 & 1,99 \\
\hline Campesinos modestos & 52 & 24,9 & 0,85 & 0,10 & 0,09 & 1,05 \\
\hline Campes. insuficientes & 126 & 60,3 & 0,35 & 0,04 & 0,07 & 0,46 \\
\hline Totales & 209 & 100 & 0,69 & 0,08 & 0,11 & 0,89 \\
\hline
\end{tabular}

C) Distribución del aprovechamiento del terrazgo (\%)

\begin{tabular}{|c|c|c|c|c|c|}
\hline Tipología social & Labradío/mixto & Viñedo & Inculto & Totales(Has) & $\%$ \\
\hline Elites campesinas & 77,8 & 7,9 & 14,3 & 21,40 & 11,6 \\
\hline Campesinos ricos & 77,8 & 8,5 & 13,6 & 51,66 & 27,9 \\
\hline Campesin. modestos & 81,4 & 9,8 & 9,0 & 54,42 & 29,4 \\
\hline Campes. Insuficientes & 76,6 & 8,9 & 14,5 & 57,50 & 31,1 \\
\hline Totales & 78,5 & 8,9 & 12,6 & 184,98 & 100 \\
\hline
\end{tabular}

24 Sobre una sólida base de 10 parroquias el nivel de bautizados habría pasado de un índice 104 en 1671/80 a 111 en 1781/90, sea un avance casi insensible que no llega al 7\% en 110 años 
No apreciamos cambios muy sensibles en la distribución social de terrazgo, ni en el tamaño de las explotaciones ni tampoco en los aprovechamientos agrícolas en cuanto al cultivo cerealero que sigue dominando en similares proporciones; no sucede así con los viñedos que retroceden a favor de los espacios incultos fruto de una mayor racionalidad que explicaría el sensible aumento de los rendimientos. Sin embargo, por debajo de esta continuidad debemos señalar algunos matices. Al combinarse la subida de los rendimientos con el alza del producto neto el nivel de suficiencia ha descendido de las 0,95 Has. de la fase anterior a las 0,86 de esta. Este cambio modesto próximo al $10 \%$ tuvo como primera consecuencia que el porcentaje de campesinos insuficientes pasara a ser del 77 al $71 \%$ y que el déficit global de la muestra que podríamos cifrar en casi un $20 \%$ ya podía ser cubierto por las rentas que, recuérdese se llevan el $21 \%$ de las cosechas, La comarca habría pasado de una situación deficitaria (-10\%) a otra de casi equilibrio $(+1,8 \%)$ y esta situación podría haber derivado en una leve mejora de los niveles de vida, tema por estudiar en nuestra zona pero que ya ha sido abordado para otras comarcas de agricultura y sociedad minifundistas muy similares ${ }^{25}$.

Es cierto que seguimos ante la presencia de una sociedad típica de minifundio donde el tono lo da la aplastante superioridad de las familias que deben complementar sus ingresos con otros alternativos volviendo endémico el fenómeno migratorio pero el papel de nuestras explotaciones excedentarias ha sufrido modificaciones sensibles: a pesar de que las cantidades derivadas de las rentas han aumentado por encima del tamaño de la muestra, los 31 campesinos excedentarios del período ya eran capaces de generar unos excedentes próximos a los 800 Hl. (789) muy próximos a los algo más de 800 de rentas (832) que se detraían de las 209 explotaciones de la muestra. Frente a lo que sucedía en la etapa anterior los excedentes productivos netos ya eran casi tan importantes como las rentas y esto no debe devaluarse.

Las tres parroquias que hemos seleccionado en el Catastro de Ensenada, que consideramos representativas, permiten constatar sensibles diferencias con nuestros inventarios a la vez que incrementan nuestras sospechas de una real ocultación en la fuente fiscal. Veámoslo en la siguiente tabla:

25 En la comarca orensana de Celanova se ha apreciado un real avance de las condiciones de vida que parecen culminar en 1760 iniciándose entonces una inversión a la baja. Vid RODRÍGUEZ FERNÁNDEZ, D., "Desigualdades sociales y criterios de consumo diferenciados. Cultura material y nivel de vida en la Galicia interior. Celanova (1630-1850)", Cuadernos Feijonianos de Historia Moderna, I, 1999, pp. 205-206 
Tabla $n^{\circ}$ 7.- La sociedad campesina a mediados del XVIII (Catastro, 1752).

A) La distribución social de la tierras en cifras medias (Has.)

\begin{tabular}{|c|c|c|c|c|c|c|}
\hline Tipología social & $\mathrm{N}^{\circ}$ casos & $\%$ & Labradío/mixto & Viñedo & Inculto & Total \\
\hline Elites campesinas & 7 & 2,15 & 2,52 & 0,93 & 3,83 & 7,28 \\
\hline Campesinos ricos & 21 & 6,44 & 1,41 & 0,28 & 1,39 & 3,08 \\
\hline Campesinos modestos & 92 & 28,22 & 0,75 & 0,17 & 0,61 & 1,53 \\
\hline Campesinos insuficientes & 206 & 63,19 & 0,26 & 0,06 & 0,19 & 0,52 \\
\hline Totales & 326 & 100 & 0,52 & 0,13 & 0,47 & 1,12 \\
\hline
\end{tabular}

B) Distribución del aprovechamiento de terrazgo (\%).

\begin{tabular}{|c|c|c|c|c|c|}
\hline Tipología social & Labradío & Viñedo & Inculto & Total Has. & $\%$ \\
\hline Elites campesinas & 34,7 & 12,7 & 52,6 & 50,93 & 13,9 \\
\hline Campesinos ricos & 45,8 & 9,1 & 45,2 & 64,58 & 17,6 \\
\hline Campesinos modestos & 48,9 & 11,1 & 40,0 & 144,01 & 39,3 \\
\hline Campesinos insuficientes & 49,7 & 12,5 & 37,8 & 106,66 & 29,1 \\
\hline Totales & 46,6 & 11,4 & 42 & 366,18 & 100 \\
\hline
\end{tabular}

Este segundo acercamiento presenta graves divergencias con el visto con anterioridad al modificarse de manera muy perceptible:

a) La distribución del terrazgo: los inventarios además de devaluar la vid, quizás por deficiencias informativas de la fuente al no separar de manera adecuada las dedicaciones de las parcelas de cultivo mixto aquí muy frecuentes nos presentan unas cantidades irrisorias de inculto. Creemos que aquí el Catastro permite corregir ambas deficiencias como lo han puesto de relieve otras escrituras notariales y diocesanas ${ }^{26}$.

b) La explotación media es sensiblemente más alta en el Catastro (1,12 Has.) que en los inventarios $(0,89$ Has.) debido precisamente a la mayor presencia del inculto en la primera fuente donde supone el $42 \%$ frente al pírrico $12,6 \%$ de los segundos. Sin embargo las cosas varían si contrastamos las espacios cultivados ya que encontraríamos 0,77 Has. en los inventarios sin duda superiores a las 0,65 Has. del Catastro y no parece casual que esta diferencia del $18 \%$ se aproxime mucho al déficit del $25 \%$ que apreciábamos en el tamaño de las parcelas. Esto modifica de manera sustancial las cifras del Catastro que creemos que pecan por defecto.

${ }^{26}$ Con un número de escrituras representativas situadas entre 1763 y 1774 el inculto representa el $37,8 \%$, porcentaje muy cercano al $42 \%$ que nos ofrece el Catastro. Vid. PÉREZ GARCÍA, J.M., "En los límites....", op cit. pp. 239-40. 
Las conclusiones derivadas del Catastro más importantes y su contraste con los inventarios serían las siguientes: 1) Las cotas sociales inferiores se ensanchan a costa de las superiores y los campesinos insuficientes sumarían a los 206 de la tabla otros 63 modestos que no lograrían el corte mínimo necesario situado en las 0,86 Has lo que equivale a decir que el porcentaje conjunto de explotaciones que no tienen garantizado el mínimo de subsistencia se elevaría al 82,5\% frente al $71 \%$ que vimos antes; 2) Los campesinos excedentarios quedan devaluados y los excedentes netos del grupo apenas superar los $500 \mathrm{Hl}$. aproximadamente la mitad de las rentas que pagan estas tres parroquias cuando antes ambos conceptos se equiparaban en los inventarios; 3) El déficit global de la muestra catastral se eleva al $38 \%$ y ya las rentas - recuérdese que representan el $21,5 \%$ - no serían suficientes para cubrirlo y se borraría de un plumazo la situación de equilibrio que deducíamos de los inventarios. La utilización del Catastro presenta muchas dudas incluso cuando se opera con las correcciones señaladas y se eligen de manera muy cuidadosa las parroquias a vaciar.

\section{LA SOCIEDAD CAMPESINA EN LA PRIMERA MITAD DEL SIGLO XIX (1791-1853)}

El contexto en que se desarrolla este modelo social presenta dos notas principales que son el generoso avance de la población superándose la larga etapa maltusiana precedente ${ }^{27}$, el segundo asalto a los comunales que quedó reflejado en un incremento de la conflictividad sobre el monte ${ }^{28}$ y en un afinamiento del modelo agrario (introducción de las praderías artificiales, perfeccionamiento del regadío, casi monopolio del maíz y avance de los rendimientos). Estos cambios se reflejaron muy bien en nuestros inventarios. Veamos:

Tabla $n^{\circ}$ 8.- La sociedad campesina en el siglo XIX (1791-1853).

A) La distribución social de la tierra en cifras medias (Has.)

\begin{tabular}{|c|c|c|c|c|c|c|}
\hline Tipología social & $\mathrm{N}^{\circ}$ casos & $\%$ & Labradío/mixto & Viñedo & Inculto & Total \\
\hline Elites campesinas & 7 & 3,8 & 2,87 & 0,26 & 1,70 & 4,83 \\
\hline Campesinos ricos & 28 & 15,4 & 1,63 & 0,17 & 1,01 & 2,81 \\
\hline
\end{tabular}

27 Podíamos estimar que la densidad de la comarca habría pasado de 114 habts/Km2 en 1790 a 128,7 en 1857. Vid. PÉREZ GARCÍA, J. M., "De la escasez ....", op. cit.

28 Para una mayor información vid. PÉREZ GARCÍA, J. M., "Las utilidades del inculto y la lucha por sus aprovechamientos en la Galicia Meridional (1650-1850)". Obradoiro de Historia Moderna, n 9,2000 , pp. 95-96. 


\begin{tabular}{|c|c|c|c|c|c|c|}
\hline Campesinos modestos & 49 & 26,9 & 0,86 & 0,16 & 0,58 & 1,59 \\
\hline Campesinos insuficientes & 98 & 53,8 & 0,31 & 0,09 & 0,20 & 0,60 \\
\hline Totales & $182 *$ & 100 & 0,76 & 0,13 & 0,49 & 1,38 \\
\hline
\end{tabular}

* Eliminadas 2 partijas aberrantes

B) Distribución del aprovechamiento del terrazgo (\%)

\begin{tabular}{|c|c|c|c|c|c|}
\hline Tipología & Labradío/mixto & Viñedo & Inculto & Total(Has) & $\%$ \\
\hline Elites campesinas & 59,5 & 5,3 & 35,2 & 33,81 & 13,5 \\
\hline Campesinos ricos & 57,9 & 6,0 & 36,1 & 78,75 & 31,6 \\
\hline Campesinos modestos & 53,9 & 9,9 & 36,2 & 78,02 & 31,3 \\
\hline Campes. Insuficientes & 50,8 & 15,4 & 33,7 & 58,88 & 23,6 \\
\hline Totales & 55,4 & 9,4 & 35,2 & 249,46 & 100 \\
\hline
\end{tabular}

La presión del avance de la población y el descenso relativo de sus precios explican la caída de las superficies vitícolas en casi todas las cotas sociales con relación a $1752^{29}$. La revalorización de los espacios incultos podría explicarnos esa alta presencia de estas superficies en los inventarios durante la fase lo que traduce a su vez una distribución muy racional de las explotaciones visible entre todos los grupos sociales. Este aumento del inculto no impidió tampoco el incremento de las superficies cultivadas pasándose de 0,77 a 0,89 Has. y se refuerza así la capacidad productiva de las explotaciones. Fruto de tales cambios fue el significativo ascenso de la explotación media que pasó de 0,89 en la fase interior a 1,38 Has. en esta. ${ }^{30}$ Por otro lado, al coincidir estos cambios con un nuevo avance de los rendimientos y con el ascenso del producto neto campesino los efectos sobre la estructura social no fueron despreciables: las explotaciones insuficientes descendieron del $78 \%$ del siglo XVII y del $71 \%$ en el XVIII a nada menos que el 60,4\% en este período final. De manera paralela los niveles superiores reforzaron sus posiciones y pasaron del $14,8 \%$ precedente al $19,2 \%$ a la par que se incrementaba su parte proporcional de la tarta (pasan de disfrutar el 39,5\% al $45,1 \%$ de las tierras además de reforzarse sus explotaciones medias cultivadas que pasaban de 1,84 a 2,07 Has. En el otro lado del abanico social los campesinos insuficientes caen en cifras relativas como vimos pero también lo hacen más sus tierras al

${ }^{29}$ Este descenso vitícola es un fenómeno generalizado de los viñedos gallegos litorales. Vid. SAAVEDRA, P., "La economía vitícola en la Galicia del Antiguo Régimen", Agricultura y Sociedad, n 92,1992 , pp. 141-44.

${ }^{30}$ No se puede acusar a la introducción de partijas en esta fase siendo muy escasas en la precedente. Si excluyéramos las 22 partijas utilizadas en este período los 160 inventarios restantes presentarían una explotación media de 1,22 Has. frente a las 1,38 de nuestra tabla. Esta desviación del 10\% creemos que puede ser asumida. 
pasar de disfrutar el 31,1\% al 23,6\%. En definitiva, estaríamos ante una sociedad reforzada por arriba y debilitada por la base desarrollándose un claro proceso de polarización en esta etapa visible también en otros modelos de sociedades rurales ${ }^{31}$.

Por último, es significativo que una muestra inferior en un 13\% con relación a la etapa precedente - 182 casos frente a 209 - era capaz de obtener un producto bruto un $10 \%$ superior al disfrutar de mayor espacio de dedicación cerealera y beneficiarse de rendimientos más altos.

Vista en su conjunto nuestra sociedad rural minifundista sigue avanzando en su cuadro estructural. De una situación deficitaria en el siglo XVII se había avanzado hacia un modelo de equilibrio en la centuria siguiente para colocarse en una situación excedentaria en esta fase final. En efecto, con una producción bruta próxima a los $4.200 \mathrm{Hl}$. de grano, se podría hacer frente a las rentas que se llevarían unos $830 \mathrm{Hl}$, al consumo necesario que subiría a poco más de $2.900 \mathrm{Hl}$. y a las semillas que se llevarían poco más de $140 \mathrm{Hl}$. Todo esto deducido del producto bruto indicado aun permitiría unos sobrantes cercanos al 8\% (331 Hl.). Los auténticos beneficiarios de esta situación fueron esas 35 explotaciones excedentarias con una cosecha que estimamos en algo más de $2.000 \mathrm{Hl}$. de las que deducidas rentas, semilla y consumo dejaría una producción neta de más de $1.000 \mathrm{Hl} .{ }^{32}$. Si recapitulamos tendríamos que a lo largo de 250 años los excedentes de este grupo no cubrían las rentas en el siglo XVII, alcanzaban a equilibrar ambas partidas en el setecientos pero ahora eran capaces de acumular un volumen tal de excedentes que superaban en un 23\% a las diversas cargas que soportaba este modelo social. 'Esta sociedad era ya excedentaria y los protocolos ya informan de que las salidas de granos al exterior eran una auténtica realidad ${ }^{33}$.

${ }^{31}$ Una demostración precisa de este proceso para el Valle del Esla puede verse en PÉREZ GARCÍA, J. M., "Niveles de vie et traditions culturelles dans les campagnes du León entre 1700 et 1850". Histoire et Sociétés Rurales, nº 8, 1997, 99, pp. 86-90.

32 Un buen ejemplo de estos campesinos excedentario lo prueba el inventario de Anselmo Vicente, vecino de Piñeiro, realizado a fines de abril a unos dos meses de empezar a recibir la nueva cosecha. No disponemos de las medidas de su explotación pero si su ganadería (una yunta de bueyes, 1 vaca con su cría, 9 cabezas de ovino y 2 de porcino) y su despensa que aún dispone de 16 Hl. de maíz, $14 \mathrm{Hl}$. de vino y pequeñas cantidades de centeno, panizo y fríjoles además de buenas reservas cárnicas ( 3 perniles, 1 unto y 8 cuartillos de grasa de cerdo). Podemos cerrar las existencias con su buen vestuario y dinero en efectivo (364 reales). A.H.P.P., F.P., Libro 29-A, 29-IV-1806

33 Tres escrituras de protesta del año 1839 y una cuarta de 1845 fueron consecuencia de problemas surgidos en los contratos de fletamento para exportar cereal de nuestra comarca en dirección a la España Cantábrica suponiendo cantidades importantes de grano que sólo en el primero de los años suponían unos 1.500 Hl. A.H.P.P., F.P., Cajas 3.876 (27-VII-1839 y 6-VIII-1839), 3.831 (21-VIII1839) y 3.842 (30-IV-1845). También salían remesas de vino desde el mismo puesto de Camposantos, situado en la desembocadura del Miño, como ocurría con el bergantín $N^{a} S^{a}$ del Carmen cuyo capitán confiesa haber recibido ya a bordo 48 pipas de vino, unos 226 Hl. A.H.P.P., F.P., Libro 65 C, 9-V-1796. 
A las desigualdades observadas en el usufructo de la tierra habría que sumar las las que se derivaban del disfrute del ganado que se nos presenta con un reparto mucho más igualitario ${ }^{34}$. Hemos analizado también a doble fuente la distribución del ganado en los siglos XVII y XVIII con la misma distribución social y con las mismas muestras ${ }^{35}$ contenidos en las tablas 6,7 y 8 ya vistas:

Tabla $n^{\circ}$ 9.- La ganadería en el Bajo Miño (1625-1790).

A) Distribución social y cifras medias de la ganadería en el siglo XVII a través de inventarios (1625-1680).

\begin{tabular}{|c|c|c|c|c|c|c|c|c|}
\hline & \multicolumn{2}{|c|}{ Vacuno } & \multicolumn{2}{|c|}{ Lanar/cabrío } & \multicolumn{2}{|c|}{ Porcino } & \multicolumn{2}{|c|}{ Total } \\
\hline Tipología & Cabezas & Media & Cabezas & Media & Cabezas & Media & Total & Media \\
\hline $\begin{array}{c}\text { Elites } \\
\text { campesinas }\end{array}$ & 15 & 3 & 98 & 19,6 & 9 & 1,8 & 122 & 24,4 \\
\hline $\begin{array}{c}\text { Ricos } \\
\text { campesinos }\end{array}$ & 58 & 2,76 & 225 & 10,7 & 39 & 1,96 & 322 & 15,33 \\
\hline $\begin{array}{l}\text { Campe. } \\
\text { modestos }\end{array}$ & 68 & 1,58 & 215 & 5,0 & 55 & 1,28 & 338 & 7,86 \\
\hline $\begin{array}{c}\text { Cam. } \\
\text { insuficientes }\end{array}$ & 122 & 1,10 & 254 & 2,29 & 79 & 0,71 & 455 & 4,10 \\
\hline Totales & 263 & 1,46 & 792 & 4,4 & 182 & 1,01 & 1237 & 6,87 \\
\hline $\begin{array}{l}\text { Explotaciones } \\
\text { sin ganado }(\%)\end{array}$ & & 33,9 & & 65 & & 39,4 & & \\
\hline
\end{tabular}

B) Mismo análisis en el siglo XVIII a través de los inventarios (1691-1790).

Vacuno

Lanar/cabrío

Porcino

Total

\begin{tabular}{|c|c|c|c|c|c|c|c|c|}
\hline Tipología & Cabezas & Media & Cabezas & Media & Cabezas & Media & Total & Media \\
\hline Elites campesinas & 12 & 2,4 & 82 & 16,4 & 13 & 2,6 & 107 & 21,40 \\
\hline Ricos campesinos & 44 & 1,5 & 30 & 1,0 & 35 & 1,2 & 109 & 3,63 \\
\hline Camps. modestos & 107 & 1,6 & 257 & 4,0 & 50 & 0,8 & 414 & 6,37 \\
\hline Cam. insuficientes & 117 & 0,8 & 193 & 1,3 & 74 & 0,5 & 384 & 2,69 \\
\hline Totales & 280 & 1,15 & 562 & 2,31 & 172 & 0,71 & 1.014 & 4,17 \\
\hline $\begin{array}{c}\text { Explotaciones } \\
\text { sin ganado (\%) }\end{array}$ & & 44,9 & & 70,8 & & 47,3 & & \\
\hline
\end{tabular}

${ }^{34}$ Si tomamos los excelentes datos ganaderos del Catastro tendríamos que nuestras 2 categorías superiores - entre ellos tres hidalgos absentistas - disfrutan del 13,4\% de las reses muy distantes del $31,5 \%$ de las tierras que le otorga esta misma fuente.

35 Sólo en la segunda fase (1681/1790) se ha ampliado de 209 casos a 243 al introducir 34 más procedentes de inventarios que no ofrecen información sobre bienes inmuebles pero si muebles y ganaderos. A falta del tamaño de la explotación fue la propia información general del inventario la que nos llevó a insertarlo en su nivel correspondiente. 
C) Idéntico análisis en el Catastro de Ensenada (1752).

Vacuno Lanar/cabrío

Porcino

Total

\begin{tabular}{|c|c|c|c|c|c|c|c|c|}
\hline Tipología & Cabezas & Media & Cabezas & Media & Cabezas & Media & Total & Media \\
\hline Elites campesinas & 12 & 3 & 27 & 6,75 & 7 & 1,75 & 46 & 11,5 \\
\hline Ricos campesinos & 68 & 3,2 & 75 & 3,6 & 32 & 1,5 & 175 & 8,53 \\
\hline Camp. modestos & 311 & 3,3 & 367 & 3,9 & 99 & 1,1 & 777 & 8,27 \\
\hline Cam. insuficientes & 227 & 1,1 & 305 & 1,5 & 126 & 0,6 & 655 & 3,16 \\
\hline Totales & 618 & 1,90 & 774 & 2,37 & 264 & 0,81 & 1.656 & 5,08 \\
\hline $\begin{array}{c}\text { Explotaciones } \\
\text { sin ganado }(\%)\end{array}$ & & 35,0 & & 62,2 & & 33,7 & & \\
\hline
\end{tabular}

La ganadería del Bajo Miño arroja cifras ya muy modestas en fechas tempranas que se acentúan en el siglo XVIII colocando a estas tierras meridionales a la cola de Galicia. Una ganadería cuantitativamente reducida pero cualitativamente importante al descansar en las especies estabuladas con una gran integración de los intereses agrarios y ganaderos que favorecen la alta productividad de la comarca ${ }^{36}$, Por último, la ganadería contribuye a aminorar las diferencias sociales internas que hemos apreciado en el reparto de la tierra sobre todo en el siglo XVIII, cuando ricos y modestos campesinos presentan niveles ganaderos similares quedando las fuertes diferencias sobre todo a nivel de los grupos extremos. Esto no debe hacernos olvidar que algo más de un tercio de las explotaciones carece de reses vacunas o porcinas pero en nuestra zona nunca encontraremos, ni siquiera en el XVII, esas espléndidas cabañas tan frecuentes en otras comarcas gallegas ${ }^{37}$.

${ }^{36}$ A pesar de que las cifras medias de ganado vacuno por vecino de la Provincia de Tuy eran con diferencia las más bajas de Galicia sin embargo en número de bovinos por Ha. de tierra de labradío/pasto se situaban entre las más altas. Vid. SAAVEDRA, P., "Petite exploitation et changement agricole à l'interieur d'un vieux 'complexe agraire'. Les campagnes de la Galice entre 1550 y 1850 ". Histoire et Société Rurales, n 12, 1999, p. 74.

37 Así en la comarca pontevedresa de la Tierra de Montes los campesinos acomodados con unas explotaciones de 4,5 a 6 Has. similares a las nuestras presentaban en el Catastro unas 50 cabezas por explotación cifras unas 5 veces superiores a las tudenses. Vid. FERNÁNDEZ CORTIZO, C., "La Tierra de Montes en la Época Moderna. Permanencias y cambios en una sociedad rural del Antiguo Régimen", Obradoiro de Historia Moderna, n 11, 2002, p. 269. 